\title{
Mössbauer spectroscopic evidence on the heme binding to the proximal histidine in unfolded carbonmonoxy myoglobin by guanidine hydrochloride
}

\author{
Taikan Harami • Shinji Kitao • Yasuhiro Kobayashi • \\ Takaya Mitsui
}

Published online: 16 September 2008

(C) The Author(s) 2008. This article is published with open access at Springerlink.com

\begin{abstract}
The unfolded heme structure in myoglobin is controversial because of no chance of direct X-ray structure analyses. The unfolding of carbonmonoxy myoglobin $(\mathrm{MbCO})$ by guanidine hydrochloride $(\mathrm{GdnHCl})$ was studied by the Mössbauer spectroscopy. The spectra show the presence of a sort of spectrum in the unfolded $\mathrm{MbCO}$, independent on the concentration of $\mathrm{GdnHCl}$ from 1 to $6 \mathrm{M}$ and the increase of the fraction of unfolded $\mathrm{MbCO}$, depending on the $\mathrm{GdnHCl}$ concentration. The isomer shift of the iron of heme in the unfolded $\mathrm{MbCO}$ was identified to be different from that of the native $\mathrm{MbCO}$ as the globin structure in $\mathrm{Mb}$ collapses under the unfolded conditions. This result and the existing related Mössbauer data proved that the heme in the unfolded MbCO may remain coordinated to the proximal histidine.
\end{abstract}

Keywords Carbonmonoxy myoglobin • Unfolding • Guanidine hydrochloride • Mössbauer spectroscopy $\cdot$ Isomer shift

\section{Introduction}

Globular proteins have a compact conformation that is essential for their biological function [1]. Proteins are synthesized in cells by a stepwise process in which amino acids are added, one by one, from the $\mathrm{NH}_{2}$-termini of the chains [2]. The protein

T. Harami $(\bowtie) \cdot$ T. Mitsui

Japan Atomic Energy Agency, 1-1-1 Kouto, Sayo-cho,

Sayo-gun, Hyogo 679-5148, Japan

e-mail: harami.taikan@jaea.go.jp

S. Kitao $\cdot$ Y. Kobayashi

Research Reactor Institute, Kyoto University,

Kumatori-cho, Sennan-gun, Osaka 590-0494, Japan 
folding is the process involved in the conversion of an ensemble of newly synthesized (or denatured) polypeptide chain conformations to the unique three-dimensional conformation of the native protein.

Myoglobin $(\mathrm{Mb})$ has its function to store oxygen molecules in the muscles. Its three-dimensional structure as the first protein was determined at atomic resolution [3]. The globin fold is made up of eight helices. The heme in Mb is embedded in a cleft (hydrophobic pocket) made up by the polypeptide chain. The molecular interactions between the heme and the protein are very complex. The heme iron is covalently linked to His93. On the other side of the heme, the distal histidine residue, His64, is one of the important residues in the control of ligand entry. The heme stabilizes intact $\mathrm{Mb}$ with respect to its apoMb [4]. The heme binding causes the pocket to collapse tightly around the porphyrin ring, resulting in a more compact protein with an $20 \%$ increase in helicity [5].

It has been known that proteins can be unfolded in aqueous solution by high concentrations of certain reagents such as guanidine hydrochloride $(\mathrm{GdnHCl})$ or urea [6]. $\mathrm{GdnHCl}$ increases the solubility of the peptide group and almost all of the amino acid chains in aqueous solutions [7]. In the presence of the denaturant, the native state exists in equilibrium with various unfolded states of the molecule. Denaturation with these chemicals is one of the primary ways of measuring the conformational stability of proteins. Conformational transitions of proteins between the folded conformation and the denatured conformation have been observed by a variety of methods, measurements of changes in optical rotatory dispersion, in circular dichroism (CD), in absorption and in fluorescence spectra [2, 6, 8]. Usually, a simple two-state model, $\mathrm{N} \rightleftarrows \mathrm{U}$, is used to analyze unfolding transitions and the difference in Gibbs free energy between the native $(\mathrm{N})$ and the unfolded (U) states, $\Delta G . \Delta G$ is assumed to depend linearly on denaturation concentration [9]. The conformational stability of the protein, i.e., the change in free energy between the two conformations in water can be estimated by $\mathrm{GdnHCl}$ denaturation curves of proteins. The free energy of unfolding of $\mathrm{Mb}$ is reported to be about $10 \mathrm{kcal} / \mathrm{mol}[10,11]$.

The complex interaction between heme and globin in $\mathrm{Mb}$ prevents a simple understanding of holoprotein stability. The protein structural deformation upon adding denaturants has been the subject of research. The unfolded heme structure in myoglobin, whether the heme is detached from the protein or the heme is intact even under the denatured condition, is controversial because of no chance of direct $\mathrm{x}$-ray structure analyses. Once if the heme is detached from the protein, the situation is complex. Many studies have been done on the kinetics of heme binding to globin since the pioneering work by Gibson and Antonini [12]. A variety of experimental results shows that the association rate constant of heme and apoMb or apohemoglobin (apoHb) is affected by the states of heme in solution i.e., free heme or nonspecific heme binding to protein (coordination to surface lysines and histidines), monomeric heme or aggregates of heme [12-21]. So far, many experiments on the unfolding of $\mathrm{Mb}$ have been done in metMb. Unfolding of $\mathrm{MbCO}$ by $\mathrm{GdnHCl}$ is known to require extremely long incubation times to reach equilibrium observed by Soret absorbance spectra [14]. Choi and Terajima reported the results of GdnHCl-induced denaturation curves of metMb, deoxyMb and $\mathrm{MbCO}$ monitored by the $\mathrm{CD}$ method [22]. The association between heme and denatured globin has been postulated as a kinetic intermediate in reconstituting the holoprotein [23]. The possibility that 
the heme might remain associated with the denatured protein has been considered in the recent studies $[22,24,25]$. It has been widely believed that the insertion of the heme group is an important posttranslational event in biosynthesis of heme proteins. Much attention has been given to refolding experiments. Chiba et al. [13] chose suitable experimental conditions where the heme exists in monomeric form. Cyanometmyoglobin was unfolded by adding the concentrated urea stock solution where cyanometmyoglobin is fully unfolded and the hemin group is released from the unfolded protein moiety and is expected to exist as a monomeric cyanide-liganded hemin. They found that there are three phases in the refolding process.

In this paper, we will show Mössbauer spectra of the unfolded $\mathrm{MbCO}$ by $\mathrm{GdnHCl}$. As far as we know, this is the first time to apply Mössbauer spectroscopy to the unfolding of $\mathrm{Mb}$ by $\mathrm{GdnHCl}$. We have chosen $\mathrm{MbCO}$ rather than metMb, because of the simple low spin ferrous spectra, a quadrupolar split doublet in $\mathrm{MbCO}$ without magnetic splitting [26]. Mössbauer spectroscopy has the merit that it can identify each component of the native $\mathrm{MbCO}$ and the unfolded MbCO. Mössbauer spectroscopy measures a number of parameters which can be related to electronic state and bonding type of the iron atom of heme each in the native $\mathrm{MbCO}$ and the unfolded $\mathrm{MbCO}$. The effects of the electronic structure on the ${ }^{57} \mathrm{Fe}$ nucleus are transmitted primarily via two hyperfine interactions in Mössbauer spectroscopy: the isomer shift and the electric quadrupole interaction [27]. The isomer shift is highly sensitive to electron density at the nucleus. The calculation of isomer shifts from first principles is difficult, but their usefulness as an empirical parameter. In general covalent ferrous and ferric materials lie in the range of $-0.3 \sim 0.3 \mathrm{~mm} / \mathrm{s}$ (relative to metallic iron). The $14 \mathrm{keV}$ excited state of ${ }^{57} \mathrm{Fe}$ has an electric quadrupole moment, corresponding to an elongation of its charge distribution along the nuclear spin axis. The electric field gradient at the nucleus in sufficiently low symmetry makes the energy shift of the system depending upon the orientation of the nuclear spin.

\section{Experimental}

Samples ${ }^{57} \mathrm{Fe}$-enriched protohemin was prepared by the method described by Adler et al. [28]. Native horse heart Mb was purchased from Sigma Chemical Co. Apomyoglobin was prepared by the method of acid acetone and purified by cellulose column. The horse heart $\mathrm{Mb}$ solution reconstituted and enriched to $90 \%$ with ${ }^{57} \mathrm{Fe}$ was purified according to the method of Ascoli et al. [29] and dissolved in Tris buffer, $\mathrm{pH}$ 7.0. MbCO sample was obtained by reducing sperm whale metMb solution with a small amount of $\mathrm{Na}_{2} \mathrm{~S}_{2} \mathrm{O}_{4}$ and by introducing $\mathrm{CO}$ gas into the mother liquid, and kept under $\mathrm{CO}$ atmosphere.

A stock $8 \mathrm{M} \mathrm{GdnHCl}$ solution was prepared. In each unfolding experiment the appropriate volume of buffer, stock $\mathrm{GdnHCl}$, and $\mathrm{MbCO}$ solution were mixed to achieve the desired $\mathrm{GdnHCl}$ concentration $(0-6 \mathrm{M})$ in a final volume of $0.3 \mathrm{~cm}^{3}$ and to a final concentration of ca. $5 \mathrm{mM} \mathrm{MbCO}$ solution. The mixed samples were placed in polyethylene sample holders, and quickly frozen in liquid $\mathrm{N}_{2}$. The unfolding process was quenched in liquid nitrogen temperature. It took about $15 \mathrm{~min}$ before frozen after mixing $\mathrm{MbCO}$ and $\mathrm{GdnHCl}$. For the unfolding of $\mathrm{MbCO}$, long time is required to reach equilibrium. Hargrove et al. [14] reported that the stability of $\mathrm{Mb}$ is 
enhanced 60 fold by reduction of iron to the ferrous deoxy state and 100 fold with $\mathrm{CO}$ coordination. They attempted unfolding of $\mathrm{MbCO}$, but extremely long incubation times were required to reach equilibrium, and often oxidation of dissociated $\mathrm{CO}$ heme occurred. Our samples in the concentration of $\mathrm{GdnHCl}$ between 1 and $5 \mathrm{M}$ may correspond to kinetically be on the way to equilibrium

Mössbauer spectroscopy The Mössbauer experiment was done with a spectrometer of the constant acceleration type and a Kr-gas filled proportional counter. Data for positive and negative acceleration were stored separately in two halves of a multichannel analyzer and then folded. The source used in this experiment was $30 \mathrm{mCi}$ of ${ }^{57} \mathrm{Co}$ diffused in $\mathrm{Rh}$ metal. The velocity scale was calibrated by using an iron foil at room temperature and the centroid of the calibration spectrum was taken as zero velocity. In each case the Mössbauer spectra were measured on the samples at liquid nitrogen temperature.

\section{Results}

The MbCO solution was unfolded by $\mathrm{GdnHCl}$ with the concentration of $1 \sim 6 \mathrm{M}$. Figure 1 shows Mössbauer absorption spectra of $\mathrm{MbCO}$ in the presence of 0,3 , and $6 \mathrm{M}$ concentrations of $\mathrm{GdnHCl}$. The spectra in 0 and $6 \mathrm{M}$ of $\mathrm{GdnHCl}$ correspond to those of the native $\mathrm{MbCO}$ and the unfolded $\mathrm{MbCO}$, respectively. The spectra in $3 \mathrm{M}$ of $\mathrm{GdnHCl}$ contain two components of the native and the unfolded $\mathrm{MbCO}$. As the $\mathrm{GdnHCl}$ concentration is increased, the fraction of the unfolded component increases. The native $\mathrm{MbCO}$ has the quadrupole splitting of $0.36 \mathrm{~mm} / \mathrm{s}$ and the isomer shift of $0.26 \mathrm{~mm} / \mathrm{s}$, independent on the concentration of $\mathrm{GdnHCl}$. The quadrupole splitting of the unfolded $\mathrm{MbCO}$ is majorly identical to that of the native MbCO. The isomer shift of the unfolded $\mathrm{MbCO}$ is $0.41 \mathrm{~mm} / \mathrm{s}$, larger than that of the native $\mathrm{MbCO}$. The quadrupole splitting $(0.37 \mathrm{~mm} / \mathrm{s})$ and the isomer shift of the unfolded $\mathrm{MbCO}$ present small dependence on the $\mathrm{GdnHCl}$ concentration. The linewidth of the spectra in the unfolded MbCO increases slightly from 0.22 to $0.27 \mathrm{~mm} / \mathrm{s}$ between 3.0 and 3.5 M. The Mössbauer spectra were composed of two components of the native $\mathrm{MbCO}$ and the unfolded $\mathrm{MbCO}$ for the concentrations of $\mathrm{GdnHCl}, 1$ to $5 \mathrm{M}$. The spectra in the unfolded $\mathrm{MbCO}$ showed a sort of spectrum without any other component for the concentrations of $\mathrm{GdnHCl}, 1$ to $5 \mathrm{M}$. Figure 2 shows the dependence of the mole fraction of the unfolded forms of $\mathrm{MbCO}$ on the $\mathrm{GdnHCl}$ concentration. The mole fractions were calculated by the ratio of the Mössbauer absorption area of unfolded to the total absorption area.

\section{Discussion}

Some evidences suggest that the unfolding of metMb results in heme dissociation $[14,23]$. However, contrary to these reports, Moczygemmba et al. [25] reported that the unfolding of metMb was reversible (up to $5 \mathrm{M} \mathrm{GdnHCl}$ ) and no protein concentration dependence was detected for the equilibrium unfolding transition, suggesting that the heme stays coordinated to the unfolding polypeptide. In the 
Fig. 1 Mössbauer absorption spectra of $\mathrm{MbCO}$ in the presence of various concentrations of $\mathrm{GdnHCl}$ at liquid nitrogen temperature. The mixed samples of $\mathrm{MbCO}$ and $\mathrm{GdnHCl}$ were kept at room temperature during $15 \mathrm{~min}$, and then quickly cooled down to liquid nitrogen temperature. Full curves are calculated spectra based upon parameters values given in the text. Dashed, and dotted curves show native $\mathrm{MbCO}$ and unfolded $\mathrm{MbCO}$, respectively

Fig. 2 Dependence of the mole fraction of unfolded forms of $\mathrm{MbCO}$ on the $\mathrm{GdnHCl}$ concentration



Fig. 3 Mössbauer parameters of the unfolded MbCO, native $\mathrm{MbCO}$, carbonyl hemochromes, and metMb

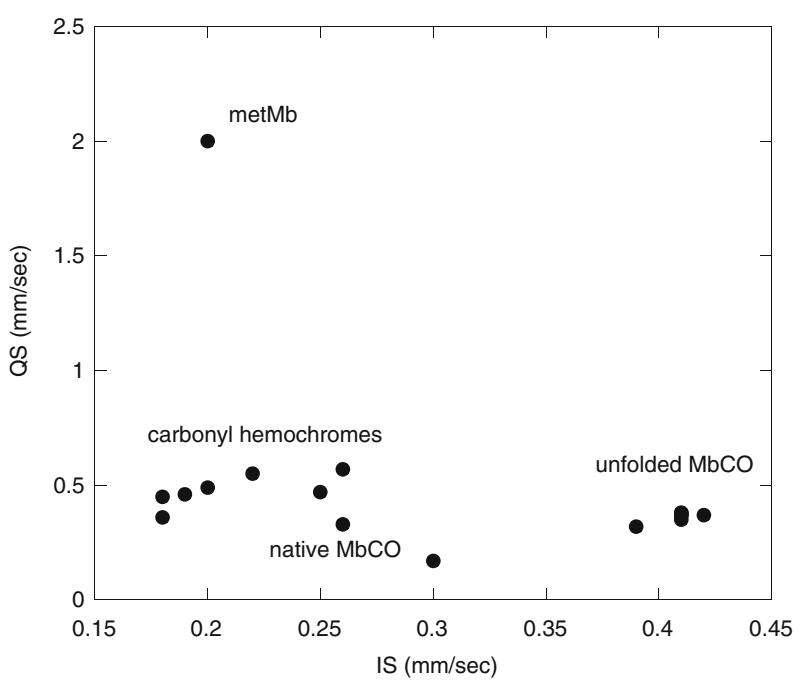

GdnHCl denaturant experiment by Choi and Terajima [22], the denaturation curve monitored by the circular dichroism (CD) intensity is well expressed by a two-state unfolding transition and any intermediate state has not been observed clearly. The destruction (or deformation) of the secondary structure ( $\alpha$-helices) can be monitored by the CD signal intensity. Changes of the diffusion coefficients of the protein determined by the transient grating (TG) method with the increasing concentration of $\mathrm{GdnHCl}$ are almost similar to those measured from the CD signal intensity [22]. They concluded that the heme in $\mathrm{MbCO}$ is intact in the protein even under the denatured condition.

If the heme is detached from the protein in the unfolded state, it will be possible either to make an intermediately nonspecific binding of heme-CO to globin $[12,14,15]$, and to unfold this intermediate completely to the unfolded state at high $\mathrm{GdnHCl}$ 
concentrations, or to make heme-CO free. The former case results in a three-state process for the denaturation of $\mathrm{MbCO}$. In our case the spectra of the unfolded $\mathrm{MbCO}$ does not basically change up to the high concentration (6 M) of $\mathrm{GdnHCl}$. This is not the case. In the latter case, Connor and Straub [30] have measured the Mössbauer spectra of several carbonyl hemochromes (nonprotein iron porphyrin carbonyls), containing six-coordinated iron (II). The carbonyl hemochromes give sharp, wellresolved quadrupolar split doublets and contain low-spin iron (II). The quadrupole splitting of the unfolded $\mathrm{MbCO}$ is in the range of values for carbonyl hemochromes and the native $\mathrm{MbCO}$ (Fig. 3), although the isomer shift of the unfolded $\mathrm{MbCO}$ is different from that of carbonyl hemochromes. The free heme- $\mathrm{CO}$ will form an aggregation of the heme, making dimers involving an oxygen atom bridging two iron ions. The Mössbauer spectra of the porphyrin dimers have been reported that the quadrupole splitting of them are in the range of $0.5 \sim 1.0 \mathrm{~mm} / \mathrm{s}$, depending on porphyrin derivatives and temperature [31]. The value is far from that of the unfolded $\mathrm{MbCO}$. From the above discussion, the heme in the unfolded $\mathrm{MbCO}$ may remain coordinated to the protein.

The influence of $\mathrm{pH}$ on ligand binding to $\mathrm{Mb}$ has been studied through His 64 and His93. It is well known that the conformation of the acid-induced denatured $\mathrm{Mb}$ is far from a randomly coiled polypeptide but is partially folded, while the strong denaturant such as $\mathrm{GdnHCl}$ and urea can induce the complete denaturation of a protein. His93 is involved in the denaturation of $\mathrm{Mb}$ at low $\mathrm{pH}$ due to its protonation and breakage of the iron-histidine bond. MetMb denatures more rapidly than $\mathrm{MbCO}$ at low $\mathrm{pH}$ and the rate of denaturation decreases with the increase in $\mathrm{CO}$ concentration. The iron-proximal histidine bond breaks in metMb and deoxyMb below $\mathrm{pH} 4$, but remains mainly intact in $\mathrm{MbCO}$ down to $\mathrm{pH} 2.6$ [32] by using the resonance Raman spectroscopic method.

Dilg et al. have measured temperature-dependent Mössbauer spectra of a partially unfolded high-potential iron protein [33], indicating an intact metal centre in spite of a protein backbone with a largely collapsed secondary structure. The partial unfolding influences the dynamic properties over the whole physiological temperature regime. The low-temperature Mössbauer dynamics of the folded and unfolded protein are nearly identical with each other. In our paper, at $80 \mathrm{~K}$, the Lamb-Mössbauer factor was assumed to be identical in the folded and unfolded $\mathrm{Mb}$. The ratio of the unfolded Mössbauer absorption area was considered to be the unfolded ratio.

In summary, the spectra show the presence of a sort of spectrum in the unfolded $\mathrm{MbCO}$, independent on the concentration of $\mathrm{GdnHCl}$ from 1 to $6 \mathrm{M}$ and the increase of the fraction of unfolded $\mathrm{MbCO}$, depending on the $\mathrm{GdnHCl}$ concentration. This experiment proved that the heme in the unfolded $\mathrm{MbCO}$ may remain coordinated to the proximal histidine, although the globin structure in $\mathrm{Mb}$ collapses under the unfolded conditions.

Acknowledgements The authors wish to gratefully acknowledge preparations of $\mathrm{MbCO}$ and unfolded MbCO samples by Miyazaki G., Division Bioengineering, Osaka University.

Open Access This article is distributed under the terms of the Creative Commons Attribution Noncommercial License which permits any noncommercial use, distribution, and reproduction in any medium, provided the original author(s) and source are credited. 


\section{References}

1. Frauenfelder, H., Wolynes, P.G., Austin, R.H.: Biological physics. Rev. Mod. Phys. 71, S419S430 (1999)

2. Anfinsen, C.B., Scheraga, H.A.: Experimental and theoretical aspects of protein folding. Adv. Protein Chem. 29, 205-300 (1975)

3. Kendrew, J.C., Dickerson, R.E., Strandberg, B.E., Hart, R.G., Davies, D.R., Phillips, D.C., Shore, V.C.: Structure of myoglobin. Nature 185, 422-427 (1960)

4. Goto, Y., Fink, A.L.: Acid-induced folding of heme proteins. Methods Enzymol. 232, 3-15 (1994)

5. Griko, Y.V., Privalov, P.L., Venyaminov, S.Y., Kutyshenko, V.P.: Thermodynamic study of the apomyoglobin structure. J. Mol. Biol. 202, 127-138 (1988)

6. Tanford, C.: Protein denaturation. Adv. Protein Chem. 23, 121-283 (1968)

7. Nozaki, Y., Tanford, C.: The solubility of amino acids, diglycine, and triglycine in aqueous guanidine hydrochloride solutions. J. Biol. Chem. 245, 1648-1653 (1970)

8. Schellman, J.A.: The thermodynamic stability of proteins. Ann. Rev. Biophys. Biophys. Chem. 16, 115-137 (1987)

9. Pace, C.N.: Determination and analysis of urea and guanidine hydrochloride denaturation curves. Methods Enzymol. 131, 266-280 (1986)

10. Bismuto, E., Colonna, G., Irace, G.: Unfolding pathway of myoglobin. Evidence for a multistate process. Biochemistry 22, 4165-4170 (1983)

11. Pace, C.N., Vanderburg, K.E.: Determining globular protein stability: Guanidine hydrochloride denaturation of myoglobin. Biochemistry 18, 288-292 (1979)

12. Gibson, Q.H., Antonini, E.: Kinetic studies on the reaction between native globin and haem derivatives. Biochem. J. 77, 328-341 (1960)

13. Chiba, K., Ikai, A., Kawamura-Konishi, Y., Kihara, H.: Kinetic study on myoglobin refolding monitored by five optical probe stopped-flow methods. Proteins, Structure, Function, and Genetics 19, 110-119 (1994)

14. Hargrove, M.S., Olson, J.S.: The stability of holomyoglobin is determined by heme affinity. Biochemistry 35, 11310-11318 (1996)

15. Rose, M.Y., Olson, J.S.: The kinetic mechanism of heme binding to human apohemoglobin. J. Biol. Chem. 258, 4298-4303 (1983)

16. Shen, L.L., Hermans, J., Jr.: Kinetics of conformation change of sperm-whale myoglobin.I. folding and unfolding of metmyoglobin following $\mathrm{pH}$ jump. Biochemistry 11, 1836-1841 (1972)

17. Shen, L.L., Hermans, J., Jr.: Kinetics of conformation change of sperm-whale myoglobin.II. characterization of the rapidly and slowly formed denatured species(D and $\left.D^{*}\right)$. Biochemistry 11, 1842-1844 (1972)

18. Ahmad, F.: Complexities in the denaturation of horse metmyoglobin by guanidine hydrochloride. J. Biol. Chem. 260, 10458-10460 (1985)

19. Kawamura-Konishi, Y., Kihara, H., Suzuki, H.: Reconstitution of myoglobin from apoprotein and heme, monitored by stopped-flow absorption, fluorescence and circular dichroism. Eur. J. Biochem. 170, 589-595 (1988)

20. Kawamura-Konishi, Y., Chiba, K., Kihara, H., Suzuki, H.: Kinetics of the reconstitution of hemoglobin from semihemoglobins and $\beta$ with heme. Eur. Biophys. J. 21, 85-92 (1992)

21. Hargrove, M.S., Barrick, D., Olson, J.S.: The association rate constant for heme binding to globin is independent of protein structure. Biochemistry 35, 11293-11299 (1996)

22. Choi, J., Terajima, M.: Denaturation of a protein monitored by diffusion coefficients: myoglobin. J. Phys. Chem. B. 106, 6587-6593 (2002)

23. Schechter, A.N., Epstein, C.J.: Spectral studies on the denaturation of myoglobin. J. Mol. Biol. 35, 567-589 (1968)

24. Wittung-Stafshede, P., Malmström, B.G., Winkler, J.R., Gray, H.B.: Folding of deoxymyoglobin triggered by electron transfer. J. Phys. Chem. A. 102, 5599-5601 (1998)

25. Moczygemba, C., Guidry, J., Wittung-Stafshede, P.: Heme orientation affects holo-myoglobin folding and unfolding kinetics. FEBS Lett. 470, 203-206 (2000)

26. Lang, G.: Mössbauer spectroscopy of haem proteins. Quart. Rev. Biophys. 3, 1-60 (1970)

27. Long, G.J.: In: Mössbauer Spectroscopy Applied to Inorganic Chemistry, vols. 1 and 2. Plenum, New York (1984)

28. Adler, D.A., Kampas, F.R., Kim, J.: On the preparation of metalloporphyrins. J. Inorg. Nucl. Chem. 32, 2443 (1970) 
29. Ascoli, F., Rossi-Fanelli, M.R., Antonini, E.: Preparation and properties of apohemoglobin and reconstituted hemoglobin. Methods Enzymol. 76, 72 (1981)

30. Connor, W.M., Straub, D.K.: Carbonyl hemochromes. Inorg. Chem. 15, 2289-2291 (1976)

31. Torréns, M.A., Straub, D.K., Epstein, L.M.: Mössbauer studies on oxo-bridged iron(III) porphines. J. Am. Chem. Soc. 94, 4160-4162 (1972)

32. Sage, J.T., Morikis, D., Champion, P.M.: Spectroscopic studies of myoglobin at low pH: heme structure and ligation. Biochemistry 30, 1227-1237 (1991)

33. Dilg, A.W.E., Granter, K., Iakovleva, O., Parak, G.P., Babini, E., Bertini, I., Capozzi, F., Luchinat, C., Meyer-Klaucke, W.: Dynamics of wild-type HiPIP: a Cys77Ser mutant and a partially unfolded HiPIP. J. Biol. Inorg. Chem. 7, 691-703 (2002) 